\title{
REVIEW
}

\section{Primary Care Physicians' Perspectives of Their Role in Cancer Care: A Systematic Review}

\author{
Renae A. Lawrence ${ }^{1,2}$, Jordana K. McLoone, PhD, B Psych ${ }^{1,2}$, \\ Claire E. Wakefield, PhD, Masters in Public Health, B Psych ${ }^{7,2}$, and Richard J. Cohn, MBBS, FRACP ${ }^{1,2}$ \\ 'School of Women's and Children's Health, UNSW Medicine, University of New South Wales, Sydney, NSW, Australia; ${ }^{2}$ Kids Cancer Centre, Sydney \\ Children's Hospital, Randwick, NSW, Australia.
}

BACKGROUND: As survival rates improve, cancer is increasingly considered a chronic illness associated with significant long-term burden and sequelae, both physical and psychological. Various models of cancer care, including primary care physician (PCP)-led and shared-care, have been proposed, though a systematic review of PCPs' perspectives of their role and challenges in providing cancer care remains lacking. This systematic review summarises available literature on PCPs' perspectives of their role in cancer care.

METHODS: Five databases (MEDLINE, MEDLINE InProcess, EMBASE, PsycINFO and CINAHL) were systematically searched using keywords and MeSH headings for articles from 1993-2015 exploring PCPs' views of their role in the care of patients/survivors of both child and adult cancers. Two independent reviewers screened abstracts for full-text review, abstracted data and performed a quality assessment.

RESULTS: Thirty-five articles representing the perspectives of 10,941 PCPs were captured. PCPs' confidence to provide care varied according to cancer phase (e.g. treatment versus survivorship), care domain (e.g. acute medical care versus psychological late effects), and disease prevalence (e.g. breast malignancies versus childhood cancers), with preferences for shared-versus independent-care models varying accordingly. Barriers included a lack of timely and specific information/ communication from oncologists and limited knowledge/lack of guidelines, as well as lack of time, remuneration and patient trust.

LIMITATIONS: The data was limited by a lack of consideration of the preferences of patients and oncologists, leading to uncertainty about the acceptability and feasibility of suggested changes to cancer care.

DISCUSSION: PCPS appear willing to provide cancer care for patients/survivors; however, they report barriers and unmet needs related to providing such care. Future research/interventions should take into account the preferences and needs of PCPs.

KEY WORDS: cancer; primary care; care management; physician satisfaction; care transitions.

J Gen Intern Med 31(10):1222-36

DOI: $10.1007 / \mathrm{s} 11606-016-3746-7$

(c) Society of General Internal Medicine 2016

Received September 29, 2015

Revised April 7, 2016

Accepted May 4, 2016

Published online May 24, 2016

\section{INTRODUCTION}

Improved screening, early diagnosis, treatment, and an aging population, have led to an increase in the number of people living with or surviving cancer, with prevalence and survival estimates projected to continue to increase dramatically in future decades. ${ }^{1,2}$ Lifetime probability rates for diagnosis of an invasive cancer are up to $45 \%$ for men and $38 \%$ for women, ${ }^{3}$ and, for many cancer types and stages, five-year survival rates have increased for both adult and childhood cancers, ${ }^{3,4}$ resulting in increased pressure being placed on health-care systems at all stages of the cancer care continuum.

In addition to the acute effects of primary disease and treatment, health professionals must also meet the needs of survivors who remain at risk of relapse, development of a second cancer, ${ }^{5,6}$ and long-term morbidity related to the physical and psychosocial late effects of their disease and/or its treatment. ${ }^{7,8}$ Providing care for childhood cancer survivors is a particular challenge, as approximately two-thirds will experience chronic late effects ${ }^{9}$ during survivorship periods, which will, on average, span six decades. ${ }^{10,11}$ Additionally, health professionals must also meet the needs of aging cancer survivors who are at increased risk of comorbid disease and increased health-care service utilisation. ${ }^{12,13}$

Oncologists located at tertiary hospitals have traditionally provided the majority of cancer treatment and routine followup for patients with cancer. ${ }^{14-16}$ However, workforce shortages in oncology, combined with an exponentially increasing number of cancer survivors, reduced the sustainability of a specialist-based model of care. ${ }^{17}$ Some researchers predict that there will be insufficient oncologists to meet the needs of cancer patients and survivors in the future, with demand predicted to rise $48 \%$ between 2005 and $2020{ }^{18}$

Oncologist-led follow-up is expensive, with other models of care, such as primary care based management, demonstrating greater cost-effectiveness than hospital-based alternatives, with minimal variation in key outcomes documented for breast cancer patients. ${ }^{14,15,19,20}$ Oncologist-led care presents additional challenges, including difficulties in maintaining patient-oncologist contact as survivors transition through life-phases (for example, childhood cancer survivors, who 
may have more than six decades of life expectancy ahead, may move away from home and their treating hospital to pursue tertiary study, careers and relationships) or should survivors reside significant distances from the treating hospital. ${ }^{21-23}$

In response to these barriers to oncologist-led follow-up, it has been suggested that primary care physicians (PCPs) may be suitable to assume a greater role in cancer care. As primary care providers, PCPs foster long-term relationships with patients and are well placed within the community to holistically manage health-care, integrating cancer care into preexisting and ongoing primary care. ${ }^{15,24}$ In terms of health outcomes, a PCP-based follow-up system may be a safe alternative to oncologist care, ${ }^{19,25}$ and in some instances patients are more satisfied with follow-up. ${ }^{26}$ PCP follow-up may also allow better continuity of care, improved individual patient support, more proactive care, and improvements in teamwork between disciplines. ${ }^{27}$

A recent rapid review suggests that while the efficacy of PCP involvement and provision of such care is restricted by limitations in knowledge, and the attitudes/beliefs of both patients and physicians, increasing PCP involvement in cancer care has promise given that it is both structured and individualised, potentially utilising clear guidelines and electronic resources. ${ }^{28,29}$

However, it is unclear whether PCPs are willing and able to fulfil this role with little to no specialist training in cancer care. ${ }^{30}$ Also unknown is whether the PCP workforce may be limited and under similar strain to hospital-based alternatives in the future. ${ }^{31}$ Survivors of childhood cancers present an additional challenge, as PCPs encounter fewer cases and have limited paediatric oncology knowledge, ${ }^{32}$ and there remains a dearth of evidence exploring the optimal model follow-up care for this population. ${ }^{33}$

A clearer understanding of PCPs' preferences for involvement in cancer care is needed to explore the feasibility of a primary care based follow-up system. The significant amount of research that has already investigated PCPs' preferences represents an opportunity to make informed changes within health-care systems and potentially increase the quality of life and survival of cancer patients. ${ }^{34}$ It is timely then that these findings be synthesised. This review therefore aimed to summarise the available evidence on PCPs' perspectives of their role within cancer care.

\section{METHOD}

\section{Data Sources and Searches}

We conducted a systematic review to investigate primary care physicians' (PCPs') views of their role in providing care for cancer patients and survivors. The inclusion criteria were studies that assessed (1) PCPs' perspectives; (2) related to the provision of patient care; in (3) cancer. Both qualitative and quantitative studies were included. This review was conducted in accordance with the PRISMA reporting guidelines. ${ }^{35}$

The following electronic bibliographic databases were searched: MEDLINE; MEDLINE In-Process \& NonIndexed Citations; EMBASE; PsycINFO and CINAHL. The same key words were used in all databases in addition to similar MeSH headings. Similar search terms were combined using 'OR' to create search themes (e.g. neoplasm OR oncol\$ OR cancer), and these themes were then combined using 'AND' [e.g. (neoplasm OR oncol\$ OR cancer) AND (general practitioner OR family physician OR primary care physician)]. The search algorithm is detailed in Table 1. Searches were limited to human studies published in English from 19932015 and excluded studies focused on cancer diagnosis only.

\section{Study Selection and Data Extraction}

The search captured 924 abstracts, 163 of which were duplicates and, thus, removed. To augment the electronic search, we also conducted manual searches of reference lists, yielding an additional nine abstracts. The resulting 770 abstracts were hand screened by the lead author to establish appropriateness for inclusion in the review and also by a trained research assistant to ensure reliability. Studies were excluded for the following reasons (ordered by most common reason for exclusion): (1) not PCPs' perspective; (2) not related to PCPs' involvement in cancer care; (3) not cancer-specific; (4) not

Table 1. Search Algorithm

\begin{tabular}{|c|c|c|c|c|}
\hline & & \multicolumn{3}{|l|}{ Search themes } \\
\hline & & Theme 1: Cancer & Theme 2: PCP & Theme 3: Patient care \\
\hline Keywords & Applied across all databases & $\begin{array}{l}\text { Neoplasm; } \\
\text { oncol\$; cancer }\end{array}$ & $\begin{array}{l}\text { General practitioner; } \\
\text { family physician; } \\
\text { primary care physician }\end{array}$ & $\begin{array}{l}\text { Physicians role; patient } \\
\text { care; attitudes of health } \\
\text { personnel }\end{array}$ \\
\hline $\begin{array}{l}\text { Subject or MeSH } \\
\text { head }\end{array}$ & $\begin{array}{l}\text { MEDLINE and MEDLINE } \\
\text { In-Process }\end{array}$ & Neoplasms & $\begin{array}{l}\text { General Practitioners; } \\
\text { Physicians, Family; } \\
\text { Physicians, Primary Care }\end{array}$ & $\begin{array}{l}\text { Physician's Role; Patient } \\
\text { Care; "Attitude of Health } \\
\text { Personnel" }\end{array}$ \\
\hline & PsycINFO & Neoplasms & $\begin{array}{l}\text { General Practitioners; } \\
\text { Family Physicians }\end{array}$ & $\begin{array}{l}\text { Health Care Delivery; Roles; } \\
\text { Health Personnel Attitudes }\end{array}$ \\
\hline Keywords & $\begin{array}{l}\text { EMBASE } \\
\text { CINAHL }\end{array}$ & $\begin{array}{l}\text { Neoplasm } \\
\text { Only key words used }\end{array}$ & General practitioner & Patient care; health personnel attitude \\
\hline
\end{tabular}

All searches refined by: English language AND humans AND year="1993-current" AND not diagnosis 
original research; (5) screening of the general population; (6) diagnosis and referral only, no provision of care; (7) prevention, e.g. smoking cessation or vaccination; (8) intervention studies; (9) genetics studies; and (10) other. Two articles were unable to be obtained and were therefore excluded. Thirty-five articles were identified as meeting all inclusion criteria. Search results and selection are detailed in Figure 1.
Each captured article was critically appraised according to pre-determined criteria, adapted from international recommendations. ${ }^{36,37}$ Two independent reviewers extracted data from the included studies and combined the data into themes to reveal trends within the data. They also assessed study quality and strength of evidence.

\section{Records identified through database searching \\ $(\mathrm{n}=924)$}

- MEDLINE and MEDLINE in

Process: 346

- EMBASE: 479

- PsychINFO: 56

- CINHAL: 43
Additional records identified through other sources

$(\mathrm{n}=9)$
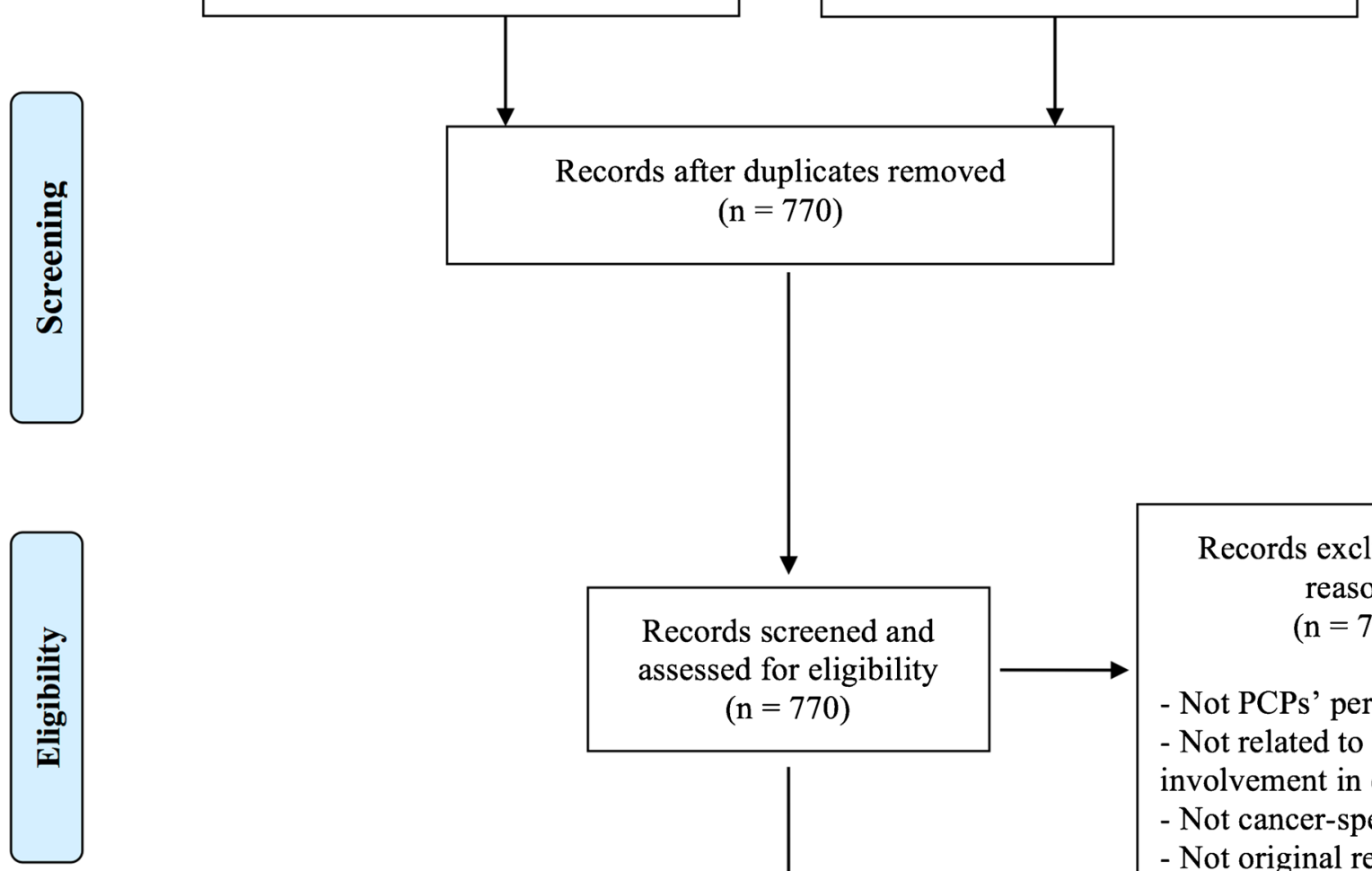

Records screened and assessed for eligibility $(\mathrm{n}=770)$

Studies included in qualitative synthesis

$$
(\mathrm{n}=35)
$$

Records excluded, with reasons

$(\mathrm{n}=735)$

- Not PCPs' perspective - Not related to PCPs' involvement in cancer care

- Not cancer-specific;

- Not original research - Screening of the general population

- Diagnosis and referral only, no provision of care - Prevention e.g. smoking cessation or vaccination - Intervention studies

- Genetics studies

- Other

Figure 1. Summary of evidence search and selection 


\section{RESULTS}

\section{Study Selection, Characteristics and Results}

The review captured 35 relevant articles representing the views of 10,941 primary care physicians (PCPs). Table 2 summarises the findings of included studies. Articles originated from 11 countries, including: United States (10), Canada (9), the Netherlands (4), Australia (3), Norway (3), France (2), United Kingdom (2), Germany (1), Italy (1), Ireland (1) and Israel (1). Two articles focused on childhood cancer survivors and the remainder were adult-focused.

\section{Quality Assessment}

All included studies had clearly described aims, methodology and used appropriate sampling procedures. However, many studies did not utilise standardised or validated outcome measures, limiting comparison across studies. Response rates were generally poor, varying between $5 \%$ and $100 \%$, with a median of $53.5 \%$. Fourteen studies failed to report a response rate. In some instances, studies reported results without exploring contextual elements, such as country-specific health care systems.

\section{PCP Preferences for Models of Care}

The majority of PCPs desired involvement in all aspects of cancer care, ${ }^{39,43}$ and approximately $55 \%$ of PCPs reported broad involvement. ${ }^{46}$ PCP involvement typically varied across the cancer trajectory with approximately $85-90 \%$ of PCPs involved in diagnosis, ${ }^{39,45,48} 45 \%$ involved during treatment and $70-80 \%$ during the survivorship phase. ${ }^{39}$ The majority of PCPs (approximately 55-65\%) believed that they should have been involved at an earlier stage of aftercare. ${ }^{44,50,68}$ Similarly, some PCPs expressed frustration at their lack of involvement during treatment, ${ }^{70}$ though others agreed that treatment was best administered in a hospital setting and need for their input was minimal. $^{38,43}$ Overall, PCPs (approximately $95 \%$ ) were consistent in their preference for a more active role in providing comprehensive patient care. ${ }^{62}$ PCPs desired involvement in areas including pain management, ${ }^{41,54,55}$ psychosocial/ emotional support, ${ }^{41,43,44,50,51,71}$ the treatment of comorbid conditions, ${ }^{42}$ health care promotion, ${ }^{46,54}$ symptom management, ${ }^{41,43}$ monitoring for recurrence, ${ }^{49}$ information provision, ${ }^{39,49}$ and the provision of accessible medical care. ${ }^{38,49}$

Approximately $50 \%$ of PCPs participating in the reviewed studies were involved in a shared model of care. ${ }^{39}$ One study reported that PCPs were prepared to accept exclusive responsibility for routine follow-up approximately two to four years from the completion of active treatment ${ }^{44}$; however, another reported that less than half of participants were willing to provide such care five years post treatment. ${ }^{64}$ The perceived benefits of a shared care model included greater psychosocial support and economic cost savings for patients and the healthcare system. ${ }^{53}$ PCPs questioned the practicality and efficiency of a standardised proactive model of care, showing preference for a demand-driven approach. ${ }^{47}$ With respect to caring for childhood cancer survivors, approximately $85 \%$ of PCPs preferred to work in consultation with a long-term follow-up program or oncologist. ${ }^{59}$

\section{Confidence to Care for Cancer Survivors}

PCPs' confidence to care for cancer survivors similarly fluctuated by stage of cancer care. Between 60 and $70 \%$ of PCPs expressed confidence in their skills for performing follow-up care $^{50,63}$; however, about half felt unprepared to manage longterm side-effects ${ }^{40}$ or conduct surveillance for recurrence. ${ }^{60}$ In general, high levels of confidence were reported for tasks such as pain management, ${ }^{55}$ conveying bad news ${ }^{71}$ and psychological support. ${ }^{50,63,64,67}$ However, lower levels of training or knowledge were reported for areas such as surveillance testing, ${ }^{60}$ active treatment or surgery ${ }^{38,54}$ and advising on complementary therapies, ${ }^{61}$ leading to a reluctance to fulfil such roles.

\section{Communication with Oncologists}

PCPs strongly endorsed improved communication with oncologists so that they could provide improved care for their patients. ${ }^{56,58,60,62,69,70}$ PCPs reported that they rarely or inconsistently received sufficient correspondence from oncologists. $^{43,48,52,58,60,67}$ Though oncologists' letters contained details on investigation and examination findings, items such as treatment/management plans, future management and expectations, goals and procedures of follow-up, and psychosocial concerns were less commonly mentioned. ${ }^{56,62}$ In one study, approximately half of PCPs reported never having received a treatment summary. ${ }^{57}$ PCPs strongly recommended improved communication with oncologists so that they could effectively treat cancerrelated issues concurrently with oncologist-led treatment of the primary malignancy. $56,58,60,62,69,70$

PCPs suggested improving post-treatment follow-up through a shared data management system, ${ }^{53}$ such as the broad integration of electronic medical records and standard communication procedures between PCPs and specialists. ${ }^{65,70}$ Provision of patient-specific standard guidelines notated by oncologists $40,44,48,59,69$ or meetings aimed at sharing information and defining roles ${ }^{38}$ were also endorsed. Electronic communication and mail were valued, ${ }^{40,58,65,69}$ but not to the exclusion of personal interaction with specialists, which was preferred. ${ }^{56,58,65}$

\section{Information Needs}

PCPs commonly reported that primary-care guidelines were not well defined or consistent for cancer survivors, ${ }^{62,70}$ and that there was a need for timely, detailed and regular transfer of information. $^{52}$ In terms of information preferences, 85-99 \% of PCPs would have liked to have received additional information from oncologists regarding cancer treatments, ${ }^{40,56,57}$ the referring PCP's role, ${ }^{56}$ findings of investigations and likely prognosis, ${ }^{56}$ the oncologist's follow-up plan, ${ }^{56,57}$ clinical practice guidelines for survivorship care, ${ }^{40}$ and potential short and long term sideeffects, including suggested management. ${ }^{56,57,69}$ PCPs suggested 
Table 2. Results Table—Studies Addressing PCPs' Perspectives of Their Role Within Cancer Care Between 1993 and 2015

\begin{tabular}{|c|c|c|c|c|c|}
\hline First author (Year) & Country of study & $n$ & Response rate & Study design & Outcomes \\
\hline Aubin $^{39}$ & Canada & 232 & $\dagger$ & $\begin{array}{l}\text { Prospective longitudinal, } \\
\text { qualitative study of patients } \\
\text { diagnosed with lung cancer. } \\
\text { Assessed 3- or 6-monthly for } \\
18 \text { months. Participants' } \\
\text { PCPs were invited to com- } \\
\text { plete a questionnaire. }\end{array}$ & $\begin{array}{l}\text { PCPs reported involvement in diagnosis } \\
(87.8 \%) \text {, treatment phase }(43.7 \%) \text {, and } \\
\text { advanced phases }(70.1 \%) \text {; shared care } \\
(48.9 \%) \text {, parallel care }(45.4 \%) \text { and } \\
\text { sequential care }(5.7 \%) \text {. PCPs desired } \\
\text { involvement in all aspects of care, } \\
\text { including information provision }(80 \%) \\
\text { and emotional support. }\end{array}$ \\
\hline Cheung $^{42}$ & Canada & 255 & $*$ & $\begin{array}{l}\text { Cross-sectional, } \\
\text { questionnaire-based study of } \\
\text { PCPs identified by respond- } \\
\text { ing survivors. Patients and } \\
\text { oncologists were also sur- } \\
\text { veyed. }\end{array}$ & $\begin{array}{l}\text { PCPs reported involvement in follow-up } \\
\text { for cancer reoccurrence }(58 \%) \text {, screening } \\
\text { for secondary cancers }(58 \%) \text {, general } \\
\text { preventative care }(79 \%) \text { and treatment of } \\
\text { other medical problems }(83 \%) \text {. PCPs } \\
\text { expected to fully fulfil the role of treat- } \\
\text { ment of other medical problems }(84 \%) \text {, } \\
\text { general preventative care }(79 \%) \text { and } \\
\text { screening for other cancers }(61 \%) \text {. For } \\
\text { follow-up of cancer reoccurrence, } 30 \% \\
\text { expected partial PCP and oncologist } \\
\text { involvement and } 54 \% \text { expected mainly } \\
\text { PCP. }\end{array}$ \\
\hline Cohen Castle $^{71}$ & Israel & 382 & $50 \%$ & $\begin{array}{l}\text { Cross-sectional survey of } \\
\text { PCPs in Israel. }\end{array}$ & $\begin{array}{l}70 \% \text { of PCPs reported confidence in } \\
\text { conveying bad news; } 5 \% \text { felt they had } \\
\text { poor or no skills. } 74 \% \text { thought discussion } \\
\text { the of emotional impact should occur } \\
\text { with patients, } 11 \% \text { would delegate to a } \\
\text { social worker and } 6 \% \text { would avoid } \\
\text { unless expressed by the patient. Barriers } \\
\text { to initiating such discussions included: } \\
\text { time constraints }(38 \%) \text { and lack of skill } \\
(13 \%) \text {. }\end{array}$ \\
\hline
\end{tabular}


Table 2.. (continued)

\begin{tabular}{lllll}
\hline \hline First author (Year) & Country of study & $\boldsymbol{n}$ & Response rate & Study design \\
\hline Dahlhaus $^{43}$ & Germany & 30 & $24 \%$ & $\begin{array}{l}\text { Qualitative interview-based } \\
\text { study of German PCPs. }\end{array}$
\end{tabular}

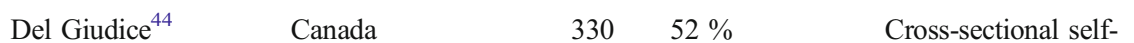
administered survey of Cana-
dian PCPs.

\begin{tabular}{|c|c|c|c|c|}
\hline Demagny ${ }^{45}$ & France and Norway & 640 & $7 \%$ and $39 \%$ & $\begin{array}{l}\text { Cross sectional, } \\
\text { questionnaire-based study of } \\
\text { PCPs in France and Norway. }\end{array}$ \\
\hline DiCicco-Bloom $^{70}$ & United States & 21 & $\dagger$ & $\begin{array}{l}\text { Qualitative study of PCPs and } \\
\text { nurse practitioners exploring } \\
\text { doctor-patient interactions } \\
\text { from initial cancer diagnosis } \\
\text { to post-treatment follow up. }\end{array}$ \\
\hline Forsythe ${ }^{46}$ & United States & 1021 & $*$ & $\begin{array}{l}\text { Cross-sectional survey of } \\
\text { medical oncologist and PCPs. }\end{array}$ \\
\hline
\end{tabular}

\section{Outcomes}

PCP involvement in cancer care varies over the course of cancer care, depending on the phase of care. PCPs expressed being less involved in curative and palliative therapy, but emphasised their fundamental role in accompanying the patient throughout the course of the disease. They demarcated their role to focus more on the patient's quality-of-life, dependent on their personal relationships, familiarity with their social environments and knowledge of the patients past medical history. They saw themselves as a resource for patients, more concerned with symptom management and the psychological dimensions of cancer care compared to a disease or treatment focus. PCPs expressed frustration with delays in information transfer and a lack of coordination of care.

PCPs were willing to assume exclusive responsibility for routine follow-up care approximately $2.5-3.5$ years following active treatment. $50 \%$ were willing to accept exclusive care within 2 years of treatment completion for breast, prostate and colorectal cancer patients. Support needed to provide exclusive follow-up included: a patient specific letter from the oncologist ( $95 \%$ ), expedited referral routes $(93 \%)$, printed guidelines $(92 \%)$ and expedited access to investigation for suspected reoccurrence $(91 \%)$. PCPs felt that they should be included at an earlier stage of follow-up care $(64 \%)$ and are better able to deliver psychosocial support $(80 \%)$. PCPs were concerned by patients' expectations to receive follow-up care from oncologists $(72 \%)$.

PCPs reported being actively involved in diagnosis $(78 \%$ in France and $83 \%$ in Norway), after the first year, 73-78\% continuing to be involved in follow-up and providing considerable psychological support.

PCPs expressed frustration at the lack of visits from patients undergoing cancer treatment. Community-based oncologists and surgeons usually provided high quality feedback compared to those in large academic centres. There are discrepancies in the summary information provided for follow-up care. PCPs suggested improving post treatment follow-up through the broad integration of electronic medical records.

$80 \%$ of PCPs reported broad

involvement in psychological care, $28 \%$ sole provision and $22 \%$ shared provision. $61 \%$ reported broad involvement in symptom management, $19 \%$ sole provision and $13 \%$ shared provision. $87 \%$ reported broad involvement in health care promotion, $51 \%$ exclusive care and $23 \%$ shared care. $53 \%$ of PCPs reported general involvement in all aspects of care. Over $60 \%$ of PCPs reported an exclusive role in treatment of anxiety or depression, counselling for smoking and treatment for sexual dysfunction. 
Table 2.. (continued)

\begin{tabular}{llllll}
\hline \hline First author (Year) & Country of study & $\boldsymbol{n}$ & Response rate & Study design & Outcomes \\
\hline Geelen $^{47}$ & The Netherlands & 53 & $\dagger$ & Qualitative study of PCPs. & PCPs expressed viewing cancer survivors
\end{tabular}

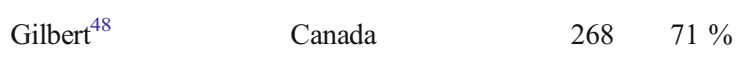

Greenfield $^{49}$

United Kingdom

54

$\dagger$

Grunfeld $^{50} \quad$ United Kingdom $\quad 180 \quad 82 \%$
Cross-sectional survey of PCPs across two regions of Ontario.

Cross-sectional e-survey of PCPs and cancer experts.

Qualitative study of PCPs of patients enrolled in a randomised trial comparing community and hospital follow-up for breast cancer. as "not special", assuming a wait-and-see (reactive) attitude and a demand-driven approach towards care, assuming cancer survivors will take the initiative to ask for help, particularly for sensitive issues such as sexual, psychological or social problems. PCPs argued that it is impossible to organise standardised proactive follow-up care as the survivorship trajectory varies considerably between patients and it was viewed as inefficient. PCPs expressed a lack of knowledge, particularly regarding other multi-disciplinary professionals available to provide care.

PCPs always assumed a significant share of the following roles in cancer care: discussing diagnosis $(85 \%)$, emotional support $(84 \%)$, prevention/screening $(83 \%)$, palliative care $(61 \%)$, pain management (58\%), coordinating care (44\%), conveying news of therapy failure $(41 \%)$ and management (39\%). Letters from regional cancer centre consultants arrived too late to be of use $(30 \%)$. 30 $50 \%$ were 'sometimes'/'seldom' satisfied and $81 \%$ were 'very often'/'often' satisfied with the content of treatment plans. $88 \%$ endorsed "a formal letter specific to diagnosis of the patient including current information on the specific cancer, prognosis, treatment options and side effects," and $50 \%$ favoured a biannual newsletter from regional cancer centres.

Highly rated reasons for follow-up included: checking for reoccurrence (94\%), reassuring patients $(87 \%)$, providing information on late effects $(83 \%)$ and to learn more about late effects $(83 \%)$. PCPs considered the advantages of primary-cared based follow-up to include: pre-existing relationships with patients $(82 \%)$, accessibility $(69 \%)$ and lower costs $(66 \%)$. PCPs felt they are appropriately located to provide supportive follow-up and may help limit feelings of abandonment that follow discharge. Major disadvantages of PCP involvement included: insufficient budgets (79\%), limited time (77\%), and lack of appropriate expertise $(75 \%)$.

$18 \%$ of PCPs agreed that hospital followup provides important psychosocial support. $69 \%$ of PCPs considered they had the necessary skills to do follow-up and $82 \%$ thought they were well located to provide psychosocial support. $53 \%$ thought that patients would prefer to see a PCP for routine follow-up and $33 \%$ thought it would be less stressful to patients. The 'most preferred' follow-up system was routine follow-up by PCPs with referral to hospital-based clinics if issues arise (69 \%). $56 \%$ of PCPs agreed they should be included earlier in breast cancer care following active treatment, $58 \%$ believed they require more training and $26 \%$ felt they receive adequately compensation to assume this role. $70 \%$ agreed that communication between PCPs and hospitals is effective. 
Table 2.. (continued)

\begin{tabular}{lllll}
\hline \hline First author (Year) & Country of study & $\boldsymbol{n}$ & Response rate & Study design \\
\hline Johansen $^{51}$ & Norway & 14 & $\dagger$ & $\begin{array}{l}\text { Qualitative study of PCPs. } \\
\text { Through purposive sampling, } \\
\end{array}$ \\
& & & $\begin{array}{l}\text { PCPs were recruited through } \\
\text { a national survey on cancer } \\
\text { and general practice. }\end{array}$
\end{tabular}

Johnson $^{52} \quad$ Australia $\quad 648 \quad 33 \%$

\begin{tabular}{|c|c|c|c|}
\hline Kerrigan $^{72}$ & Ireland & 81 & $66 \%$ \\
\hline Kisker $^{53}$ & United States & 97 & $71 \%$ \\
\hline
\end{tabular}

Klabunde $^{54}$

United States

1694

Larue $^{55}$

France

$600 \dagger$

\section{Outcomes}

PCPs saw themselves as interpreters from the first consultation, translating, reiterating and re-evaluating the medical explanation. PCPs saw talks as difficult if relaying the diagnosis. PCPs saw themselves as someone patients had confidence in but could lack specific knowledge when requested, emerging as the nearest doctor to call in acute situations but depended on a good discharge letter. Many saw themselves as team workers and companions. The relationship with the patient was seen as an important, as supporters of the patients/families and as a guide, but not all felt close to the patient due to organisational or personal reasons.

Cross-sectional survey of a random sample of Australian PCPs.

PCPs were interested in being involved in prevention $(86 \%)$, diagnosis $(86 \%)$, monitoring for reoccurrence $(70 \%)$, psychological support (69.6\%), followup after treatment $(69 \%)$ and palliative care $(68 \%)$. Five themes emerged importance of involvement and role of PCPs; need for detailed, timely and regular communication; influence of location (i.e. increasing involvement of rural PCPs); training; and barriers to caring for patients with cancer. Barriers included: lack of skill, time, resources and poor remuneration.

Qualitative study of breast cancer survivors and PCPs.

transfer of follow-up care to the community. The barriers affecting transfer were increased workload $(87 \%)$, cost $(83 \%)$ and medicolegal risk $(83 \%)$.

PCPs reported a shared management system comforted the family, relieved anxiety and provided economic benefits, allowing for more treatment choices to be offered. They rejected that the system required too much time, record keeping or money; rather, it strengthened their relationship with university physicians and was personally satisfying and educational. They expressed a need for a facsimile system where information could be shared, and a patient financial counsellor or reimbursement specialist. PCPs assumed or comanaged the role of managing comorbid conditions (98\%), evaluating and/or treating depression (95\%), ascertaining DNR status (95\%), hospice referrals $(95 \%)$ and prescribing pain medication $(91 \%)$. PCPs were more likely to comanage than directly preform cancer-specific roles, e.g. evaluating patient treatment preferences $(64 \%)$ and deciding potential uses of surgery $(53 \%)$. $85 \%$ of PCPs were satisfied with their practice of cancer pain management and $60 \%$ were content with the management of cancer pain in France. $27 \%$ reported receiving training in cancer pain management. 
Table 2.. (continued)

\begin{tabular}{|c|c|c|c|c|c|}
\hline First author (Year) & Country of study & $n$ & Response rate & Study design & Outcomes \\
\hline $\mathrm{McConnel1}^{56}$ & Australia & 108 & $54 \%$ & $\begin{array}{l}\text { Cross-sectional survey of } \\
\text { medical oncologists, radiation } \\
\text { oncologist, surgeons and } \\
\text { PCPs. Semi-structured inter- } \\
\text { views were conducted with } \\
\text { doctors and content analysis } \\
\text { of referral and reply letters. }\end{array}$ & $\begin{array}{l}\text { PCPs' preferences for letter content: } \\
\text { oncologist's specific instructions to the } \\
\text { referring PCP ( } 99 \%) \text {, a follow-up plan } \\
(98 \%) \text {, test/findings on investigation } \\
(98 \%) \text {, aim of treatment }(97 \%) \text {, likely } \\
\text { prognosis }(95 \%) \text {, likely short and long- } \\
\text { term side effects }(93 \%) \text {, what the patient } \\
\text { has been told }(92 \%) \text {, rationale for } \\
\text { recommended treatment }(92 \%) \text { and } \\
\text { management of side effects }(92 \%) \text {. } \\
\text { Oncologists' letters actually contained } \\
\text { information on examination/investigation } \\
\text { findings; however, other items were rarely } \\
\text { mentioned. } 78 \% \text { of PCPs identified } \\
\text { situations where a phone call would be } \\
\text { desirable over a letter. }\end{array}$ \\
\hline Merport $^{57}$ & United States & 400 & $11 \%$ & $\begin{array}{l}\text { Cross-sectional mailed survey } \\
\text { of cancer specialist physicians } \\
\text { and PCPs. }\end{array}$ & $\begin{array}{l}54 \% \text { of PCPs reported ever having } \\
\text { received a cancer treatment summary. } \\
\text { Information PCPs would like to be } \\
\text { included in a cancer treatment summary: } \\
\text { summary of previous treatments }(95 \%) \text {, } \\
\text { schedules for follow-up }(89 \%) \text {, recom- } \\
\text { mendations for PCPs }(89 \%) \text {, likely side- } \\
\text { effects of treatment }(84 \%) \text {, future treat- } \\
\text { ment related health risks }(67 \%) \text { and } \\
\text { health insurance }(14 \%) .\end{array}$ \\
\hline Mitchell $^{58}$ & Australia & 12 & $\dagger$ & $\begin{array}{l}\text { Qualitative study of } \\
\text { Australian PCPs. Three two- } \\
\text { hour focus groups were con- } \\
\text { ducted with non/metropolitan } \\
\text { PCPs }\end{array}$ & $\begin{array}{l}\text { Communication problems and referral } \\
\text { delays were reported (especially in non- } \\
\text { metropolitan areas), the improvement of } \\
\text { standard communication procedures be- } \\
\text { tween PCPs and public hospital special- } \\
\text { ists was recommended. Electronic } \\
\text { communication was valued, but interac- } \\
\text { tion with oncologists was preferred. PCPs } \\
\text { felt under-involved in ongoing surveil- } \\
\text { lance, and their skills under-appreciated. }\end{array}$ \\
\hline Nathan $^{59}$ & $\begin{array}{l}\text { United States and } \\
\text { Canada }\end{array}$ & 1124 & $45 \%$ & $\begin{array}{l}\text { Quantitative parallel survey } \\
\text { studies mailed to PCPs in the } \\
\text { United States and Canada. }\end{array}$ & $\begin{array}{l}1 \% \text { of PCPs preferred to care for } \\
\text { childhood cancer survivors independently, } \\
85 \% \text { preferred in consultation with a } \\
\text { long-term follow-up program or cancer } \\
\text { centre-based physician and } 11 \% \text { pre- } \\
\text { ferred to refer survivors. } 94 \% \text { considered } \\
\text { a patient-specific standardised letter from } \\
\text { specialist with surveillance recommenda- } \\
\text { tions as useful and } 93 \% \text { considered } \\
\text { access to long-term follow-up guidelines } \\
\text { to paediatric cancer survivors useful. } \\
38 \% \text { of PCPs reported having commu- } \\
\text { nicated with a colleague about survivor- } \\
\text { ship, } 33 \% \text { attended relevant continuing } \\
\text { medical education activities, } 33 \% \text { read } \\
\text { one or more journal articles on survivor- } \\
\text { ship, } 23 \% \text { attended a formal lecture } \\
\text { during training and } 18 \% \text { attended a } \\
\text { session at a professional conference. }\end{array}$ \\
\hline Nissen $^{60}$ & United States & 132 & $75 \%$ & $\begin{array}{l}\text { Cross-sectional survey mailed } \\
\text { to PCPs. }\end{array}$ & $\begin{array}{l}52 \% \text { of PCPs were very/comfortable } \\
\text { assuming responsibility of recurrence } \\
\text { surveillance and } 43 \% \text { are very/confident } \\
\text { they are following standard guidelines. } \\
\text { Ambiguity about the nature, frequency } \\
\text { and extent of surveillance testing was } \\
\text { expressed by the majority of PCPs. PCPs } \\
\text { suggested a desire for increased commu- } \\
\text { nication with oncologists; for example, } \\
\text { specific surveillance plans, and that the } \\
\text { transfer of care should be formalised. }\end{array}$ \\
\hline
\end{tabular}


Table 2.. (continued)

\begin{tabular}{lllll}
\hline \hline First author (Year) & Country of study & $\boldsymbol{n}$ & Response rate & Study design \\
\hline O'Beirne $^{61}$ & Canada & 28 & $\dagger$ & $\begin{array}{l}\text { Qualitative interview-based } \\
\text { study with PCPs. }\end{array}$
\end{tabular}

$\begin{array}{lll}\text { Paradiso }^{62} \quad \text { Italy } 263 \quad 66 \% & \begin{array}{l}\text { Questionnaire sent to PCPs, } \\ \text { regional specialists and } \\ \text { patients, regarding breast } \\ \text { cancer follow-up. }\end{array}\end{array}$

$\begin{array}{lll}\text { Potosky }^{63} \quad \text { United States } & 1072 *\end{array}$

Cross-sectional questionnaire survey of a nationally representative sample of PCPs and medical oncologists.

Cross-sectional survey of PCPs located in the three northern providences of the Netherlands.

Roorda $^{64}$

The Netherlands

502

$53 \%$

$\operatorname{Sada}^{65}$

United States

6

$\dagger$

\section{Outcomes}

PCPs struggled with the defining of complimentary therapies and expressed that there was more to medicine then the physical body. Many PCPs agreed on the importance of scientific evidence, some questioned the value of evidence-based medicine as it conflicted with treating the whole patient, especially beliefs and spirituality. PCPs attitudes towards complimentary therapies ranged from complete lack of support to actively offering them to patients. PCPs recognised that their lack of knowledge could affect doctor-patient communication. PCPs identified support, education and protection from harm as their role with complimentary therapies.

In $85 \%$ of cases, patients were generally followed-up by two or more specialists. $93 \%$ of PCPs reported to prefer a more active role in the management of followup of patients. $78 \%$ agreed that they usually do not receive any information on the goals and procedures of follow-up as dictated by the specialist.

$38 \%$ of PCPs preferred shared care, $25 \%$ preferred oncologist-led and $10 \%$ preferred PCP-led. $59 \%$ (breast cancer) and $58 \%$ (colon cancer) felt that PCPs have the required skills to preform follow-up care; $75 \%$ (breast cancer) and $74 \%$ (colon cancer) felt PCPs have the required skills to initiate screening and diagnostic tasks to detect cancer reoccurrence; and $51 \%$ (breast and colon cancer) felt that PCPs are better able to provide psychosocial support in comparison to oncologists.

During follow-up, PCPs reported

enquiring about patient symptoms (74\%), carrying out clinical breast exams $(73 \%)$ and requesting mammograms $(63 \%)$.

$80 \%$ of PCPs felt their current

contribution to follow-up was 'just right'. $40 \%$ were willing to accept exclusive responsibility 5 years from completion of treatment and $19 \%$ immediately or $1-2$ years after. The major barriers to assuming responsibility at an earlier stage were: patient preference for specialist-led care $(65 \%)$, personal knowledge and skills $(52 \%)$ and workload pressure $(36 \%)$. Compared to specialists, $61 \%$ felt they were better at providing psychological support. A patient-specific letter with a follow-up focus from specialists was considered the most useful tool in the transfer of care.

PCPs felt electronic health records (EHR) improved communication and efficiencyaccessibility, limiting the need to contact oncologists for basic information. Difficulties were identified in communicating with physicians outside of hospitals. PCPs still valued direct communication with oncologists e.g. via phone or email, for specific urgent problems. PCPs acknowledged that their role in cancer care diminishes during the treatment phase, particularly for comorbid conditions, discussed the need to assume a more assertive role and identified additional roles they could fill during active treatment (support for psychological distress and maintenance of healthy behaviour modification and goal setting). 
Table 2.. (continued)

\begin{tabular}{|c|c|c|c|c|c|}
\hline First author (Year) & Country of study & $n$ & Response rate & Study design & Outcomes \\
\hline van Roosmalen ${ }^{66}$ & The Netherlands & 15 & $100 \%$ & $\begin{array}{l}\text { Qualitative interview-based } \\
\text { study of PCPs. }\end{array}$ & $\begin{array}{l}\text { PCPs reported a lack of specialist } \\
\text { knowledge to care for cancer patients at } \\
\text { home and an inability to remain informed } \\
\text { on developments in oncology. In caring } \\
\text { for patients, PCPs reported using } \\
\text { technical medical knowledge (e.g. } \\
\text { physical examinations), the medical } \\
\text { system (e.g. consult colleagues), arranged } \\
\text { necessary affairs at home and employed } \\
\text { an understanding of what it means to } \\
\text { suffer from cancer. This knowledge was } \\
\text { obtained though medical education, } \\
\text { literature, experiences, colleagues, } \\
\text { common sense and through the patient } \\
\text { narrative. }\end{array}$ \\
\hline Wind $^{67}$ & The Netherlands & 87 & $46 \%$ & $\begin{array}{l}\text { Cross-sectional survey of } \\
\text { colorectal surgeons, patients } \\
\text { (participating in a colon } \\
\text { cancer follow-up program) } \\
\text { and PCPs. }\end{array}$ & $\begin{array}{l}\text { PCPs did not feel involved in current } \\
\text { specialist-led follow-up, partly due to a } \\
\text { lack of communication. } 30.1 \% \text { of PCPs } \\
\text { felt future colonic cancer follow-up } \\
\text { should be PCP-led ( } 34.1 \% \text { for low risk } \\
\text { patients and } 19.1 \% \text { for high risk) and } \\
50.6 \% \text { for low risk and } 36.4 \% \text { for high } \\
\text { risk patients agreed with surgeon-led } \\
\text { follow-up for the first } 2 \text { years followed by } \\
\text { PCP-led follow-up. PCPs reported high } \\
\text { levels of trust in their capabilities for } \\
\text { identifying and treating psychological } \\
\text { problems }(95.3 \%) \text {, social problems } \\
(94.1 \%), \text { lower levels were reported for } \\
\text { identifying and treating cancer related } \\
\text { physical problems }(55.8 \%) \text { and detecting } \\
\text { recurrence }(30.1 \%) \text {. }\end{array}$ \\
\hline Worster $^{68}$ & Canada & 154 & $82 \%$ & $\begin{array}{l}\text { Cross-sectional survey of } \\
\text { PCPs. }\end{array}$ & $\begin{array}{l}53 \% \text { of PCPs reported having been } \\
\text { involved in } 5 \text {-year follow-up care for a } \\
\text { patient with stage I breast cancer and } \\
64 \% \text { responded that they had some } \\
\text { familiarity with the protocols. } 77 \% \\
\text { thought it appropriate for PCPs to follow } \\
\text { most cases, } 19 \% \text { thought PCPs had a } \\
\text { follow-up role in some cases and } 4 \% \\
\text { thought it inappropriate. } 90 \% \text { would } \\
\text { accept responsibility if asked by their } \\
\text { patient. } 90 \% \text { reported they would prefer } \\
\text { to start follow-up within a year of } \\
\text { treatment completion. }\end{array}$ \\
\hline Zitzelsberger $^{69}$ & Canada & 13 & $5 \%$ & $\begin{array}{l}\text { Qualitative interviews of } \\
\text { PCPs from Ontario, Canada. }\end{array}$ & $\begin{array}{l}\text { PCPs wanted guidelines on screening, } \\
\text { treatment and follow-up. PCPs saw } \\
\text { guidelines as a possible means of } \\
\text { communication between themselves and } \\
\text { cancer centres, potentially including } \\
\text { notations from oncologists about } \\
\text { individual patients so PCPs could have } \\
\text { the necessary skills to provide on-going } \\
\text { cancer care and support for patients } \\
\text { throughout active treatment and follow- } \\
\text { up. PCPs stressed that information needs } \\
\text { to be circulated amongst all physicians } \\
\text { and mail was considered most viable. } \\
\text { PCPs agreed patient-specific written } \\
\text { guidelines would be beneficial if they } \\
\text { were clear, well written and not } \\
\text { conflicting, giving weight to PCPs' rec- } \\
\text { ommendations. }\end{array}$ \\
\hline
\end{tabular}

* only overall response rate reported, combining PCPs and other physicians or patients

+ response rate not reported

a need for more information from oncologists, such as through survivorship care plans (SCP), ${ }^{57}$ enabling them to provide ongoing care. $^{69}$

For the management of paediatric cancer survivors, one study reported that $30-40 \%$ of PCPs had participated in a conversation with a colleague about survivorship care, participated in medical education activities, or read one or more survivorship articles, and approximately $20 \%$ had experienced formal training, possibly as distant as during their undergraduate studies. ${ }^{59}$ 


\section{Barriers}

Commonly endorsed barriers to PCP delivery of cancer care included lack of expertise or formal training, ${ }^{40,48,49,52,59,64,66,71}$ lack of time and workload pressure, ${ }^{49,52,64,71,72}$ lack of remuneration and inadequate funding, ${ }^{49,52,72}$ lack of patient trust, ${ }^{44,64}$ inadequate resources including cancer-specific guidelines and opportunities for mental health or multi-disciplinary referrals $^{40,47,52,60,69}$ and increased medicolegal risk. ${ }^{72}$ Qualitative and quantitative results are summarized in Table 3.

\section{DISCUSSION}

\section{Summary of Evidence}

This review identified 35 studies representing 10,941 primary care physicians' (PCPs') perspectives of their role in caring for cancer patients and survivors. The review findings support a model of shared-care, encompassing collaboration between oncologists and PCPs that is fostered throughout the cancer trajectory, not just after the completion of active treatment. It also suggests that shared care should continue into the early survivorship period for adults, and in a possibly ongoing manner for paediatric cancers. Shared care can be fostered through the use of well-designed information transfer.

In order to meet the needs of cancer patients and survivors, various models of care have been proposed including shared care, parallel care and sequential care. ${ }^{39}$ However, conclusive evidence has not yet determined which model may be most effective. PCPs have indicated an interest in increasing their role in cancer patient care ${ }^{39,42,46}$; however, PCPs' limited confidence $^{38,40,54,60,61}$ and ability ${ }^{40,49,52,59,64,66,71}$ to perform the various roles pose a challenge. It appears that PCP confidence levels fluctuate along the cancer care continuum and according to the type of care needed. High confidence was reported for non-cancer specific tasks such as pain management and psychosocial support, ${ }^{50,55,63}$ while confidence was lower for active treatment, surveillance testing and management of long-term effects, ${ }^{38,40,54,60}$ suggesting PCPs are willing but feel unprepared to manage certain aspects of cancerspecific care. This may be attributed to PCPs' reports of minimal formal training in survivorship care, the lack of appropriate guidelines, insufficient contact with oncologists and insufficient experience. ${ }^{30,38,40,50,59,69}$ Improving PCP confidence to deliver cancer care is critical before a model of shared care is recommended.

Other barriers, such as poor remuneration for cancer-related services and lack of protected time and resources to upskill, may need to be further considered to support models of shared care. Few captured studies referred to the amount of support PCPs had or had not received to increase their knowledge of cancer care. ${ }^{5,59}$ It has been suggested systematic communication pathways, specific information, shared electronic patient records, direct contact with oncologists, clearly defined roles and adequate remuneration are needed. $38,40,44,48,51,52,56-60,65,69,70$

Cancer is not the major focus of PCPs' work and for timeand resource-poor PCPs; greater effort is often diverted into other more common chronic diseases. ${ }^{73}$ The literature suggests that PCPs valued regular and detailed systems of information sharing ${ }^{52}$ such as patient-specific guidelines ${ }^{40,44,59,69}$ or surveillance/care plans relating to their particular patient ${ }^{40,56,57,60,69}$ rather than generalised training. With over 200 different cancer diagnoses, varying patient responses to treatment and continued advances within the medical field, cancer care is both complex and highly individualised. Thus, generalised information and training quickly becomes outdated and is less useful within this context. Therefore, the challenge of sufficiently informing PCPs appears to be closely

Table 3. Barriers to PCP Delivery of Cancer Care

\begin{tabular}{|c|c|c|}
\hline Barrier & Quantitative results & Qualitative results \\
\hline $\begin{array}{l}\text { Expertise or formal } \\
\text { training }\end{array}$ & $\begin{array}{l}\text { - Lack of expertise or skill identified by } 52-75 \% \text { of PCPs }{ }^{49,64} \\
\text { - Lack of skill in discussing emotions identified by } 13 \% \text { of } \mathrm{PCPs}^{71} \\
\text { - Limited formal knowledge of survivorship care identified by } 47 \% \\
\text { of PCPs } \\
\text { - Desire for formal training in breast cancer follow-up identified by } \\
58 \% \text { of PCPs }\end{array}$ & $\begin{array}{l}\text { - Lack of skill and specialist knowledge identified } \\
\text { as barrier } 52,66 \\
\text { - Inability to remain informed on developments in } \\
\text { oncology identified as barrier }{ }^{66}\end{array}$ \\
\hline $\begin{array}{l}\text { Time and workload } \\
\text { pressure }\end{array}$ & $\begin{array}{l}\text { - Increased workload pressure/limited time if involvement was to be } \\
\text { increased identified by } 36-87 \% \text { of PCPs }{ }^{49,64,72} \\
\text { - Limited time for discussing emotions identified by } 38 \% \text { of } \mathrm{PCPs}^{71}\end{array}$ & - Lack of time identified as barrier ${ }^{52}$ \\
\hline $\begin{array}{l}\text { Remuneration or } \\
\text { funding } \\
\text { Patient trust }\end{array}$ & $\begin{array}{l}\text { - Insufficient budget or increased cost identified by } 79-83 \% \text { of } \\
\text { PCPs }{ }^{49,72} \\
\text { - Patient preference or expectation for specialist-led care identified by } \\
65-72 \% \text { of PCPs }{ }^{44,64}\end{array}$ & - Poor remuneration identified as barrier ${ }^{52}$ \\
\hline $\begin{array}{l}\text { Resources including } \\
\text { guidelines }\end{array}$ & $\begin{array}{l}\text { - Lack of standards for providing survivorship care identified by } \\
53 \% \text { of PCPs } \\
\text { - Inadequate access to mental health referrals for providing } \\
\text { survivorship care identified by } 46 \% \text { of PCPs }\end{array}$ & $\begin{array}{l}\text { - Lack of general resources identified as barrier }{ }^{52} \text {; } \\
\text { specifically: } \\
\text { - Knowledge of multidisciplinary professionals } \\
\text { available to provide care }{ }^{47} \\
\text { - Communication from oncologists }{ }^{60} \\
\text { - Specific patient information, e.g. surveillance } \\
\text { plans } 60 \\
\text { - Guidelines, e.g. for screening, treatment and } \\
\text { follow-up } 69\end{array}$ \\
\hline Medicolegal risk & - Medicolegal risk identified by $83 \%$ of $\mathrm{PCPs}^{72}$ & \\
\hline
\end{tabular}


linked to developing resources that are patient-specific, easily accessed and current, and are able to be continually updated as care needs change. Patient-specific guidelines with the integration of a 'look-up' electronic general education resource could prove useful to overcoming knowledge and time-based barriers, ${ }^{29}$ and would likely increase PCPs' confidence in caring for cancer patients and survivors.

Cancer care within the United States (US) remains a particular challenge as international trends of workforce shortages in oncology combined with growth of patient populations are felt. ${ }^{17}$ Despite PCPs' interest in an increased role in aspects of cancer care, the trajectory of care is often fragmented among various specialities. ${ }^{74}$ The findings of this review are especially useful for generalists in the US - where one-third of included studies originate - providing a summary of evidence to begin discussion surrounding altering the existing model of care taking into account the preferences of PCPs and the unique features of the US healthcare system.

Finally, childhood cancer survivors pose a unique challenge for PCPs in cancer care. There is a dearth of literature directly addressing the PCP's role as related to caring for this specific group. ${ }^{53,59}$ As paediatric cancer survivors are rarely encountered by PCPs, building this area of specialty in the general practice setting remains an exciting field of research to be further investigated.

\section{Study Limitations}

This review included only studies exploring the PCPs' perspective of their role within cancer care. However, it is essential that any changes to the current model of care should also be congruent with the preferences of oncologists and patients. Of the 35 included studies, in addition to investigating PCP preferences, 11 of the studies also explored the views of oncologists and/or patients (see ${ }^{39,42,46,49,50,56,57,62,63,65,72}$ for recent studies of patient and oncologist preferences); however, these results were not reported as part of this review. The search strategy also excluded intervention studies; however, these may objectively provide information regarding viable models of care, beyond PCPs' personal preferences. Additionally, as studies originated from 11 countries, each with different models of health care, payment systems and doctor-patient ratios, this limits the potential for dissemination of information on an international level.

\section{CONCLUSIONS}

In light of PCPs' perspectives and preferences, the feasibility of increasing the role of PCPs in cancer care remains unknown. However, given adequate support, PCPs are willing to increase their role in cancer care, with potential medical and economic benefits for patients, oncologists and the health care system.
Contributors: We would like to thank Sixuan Lin for her contributions to this research.

Corresponding Author: Claire E. Wakefield, PhD, Masters in Public Health, B Psych; Kids Cancer Centre, Sydney Children's Hospital, Level 1, High St, Randwick, NSW, Australia 2031 (e-mail: c.wakefield@unsw.edu.au).

\section{Compliance with Ethical Standards:}

Funding: This study was funded by the Kids Cancer Alliance, which is supported by a translational research grant from the Cancer Institute of NSW. Claire Wakefield is supported by a Career Development Fellowship from the National Health and Medical Research Council of Australia (APP1067501). The Behavioural Sciences Unit is supported by the Kids with Cancer Foundation. Study sponsors did not have any input into the study design, data collection or analysis, report composition or editing, or publication decisions.

Conflict of interest statement: The authors declare that they do not have a conflict of interest.

\section{REFERENCES}

1. Australian Institute of Health and Welfare. Older Australia at a glance (4th ed.). Australian Government Department of Health and Ageing, 2007.

2. Shulman LN, Jacobs LA, Greenfield S, et al. Cancer care and cancer survivorship care in the United States: will we be able to care for these patients in the future? J Oncol Pract. 2009;5(3):119-123.

3. Siegel R, Naishadham D, Jemal A. Cancer statistics, 2012. CA Cancer J Clin. 2012;62(1): 10-29.

4. Grunfeld E. Cancer survivorship: a challenge for primary care physicians. Br J Gen Pract. 2005;55(519):741-742.

5. Seehusen DA, Baird D, Bode D. Primary care of adult survivors of childhood cancer. Am Fam Physician. 2010;81(10): 1250.

6. Friedman DL, Whitton J, Leisenring $\mathbf{W}$, et al. Subsequent neoplasms in 5-year survivors of childhood cancer: the Childhood Cancer Survivor Study. J Natl Cancer Inst. 2010;102(14):1083-1095.

7. Freyer DR. Transition of care for young adult survivors of childhood and adolescent cancer: rationale and approaches. J Clin Oncol. 2010;28(32):4810-8.

8. Mertens AC, Yasui Y, Neglia JP, et al. Late mortality experience in fiveyear survivors of childhood and adolescent cancer: the Childhood Cancer Survivor Study. J Clin Oncol. 2001;19(13):3163-3172.

9. Oeffinger KC, Mertens AC, Sklar CA, et al. Chronic health conditions in adult survivors of childhood cancer. N Engl J Med. 2006;355(15):15721582.

10. Geenen MM, Cardous-Ubbink MC, Kremer LC, et al. Medical assessment of adverse health outcomes in long-term survivors of childhood cancer. JAMA. 2007;297(24):2705-2715.

11. Parsons SK, Brown AP. Evaluation of quality of life of childhood cancer survivors: a methodological conundrum. Med Pediatr Oncol. 1998;30(S1):46-53.

12. Stafford RS, Cyr PL. The impact of cancer on the physical function of the elderly and their utilization of health care. Cancer. 1997;80(10):19731980.

13. Repetto L, Venturino A, Vercelli M, et al. Performance status and comorbidity in elderly cancer patients compared with young patients with neoplasia and elderly patients without neoplastic conditions. Cancer. 1998;82(4):760-765.

14. Grunfeld E, Gray A, Mant D, et al. Follow-up of breast cancer in primary care vs specialist care: results of an economic evaluation. $\mathrm{Br} \mathrm{J}$ Cancer. 1999;79(7/8): 1227.

15. Brennan M and Jefford M. General practitioner-based models of posttreatment follow-up. in Cancer Forum. The Cancer Council Australia. 2009.

16. Jiwa M, Saunders CM, Thompson SC, et al. Timely cancer diagnosis and management as a chronic condition: opportunities for primary care. Med $\mathrm{J}$ Aust. 2008; 189(2):78-82.

17. Centre for Workforce Studies. Forcasting the supply of and demand for oncologists: A report to the American Society of Clincal Oncology (ASCO) from the AAMC Centre for Workforce Studies. 2007. Available at: http:// www.asco.org/sites/default/files/oncology_workforce_report_final.pdf. Accessed May 2, 2016 
18. Erikson C, Salsberg E, Forte G, Bruinooge S, Goldstein M. Future supply and demand for oncologists: challenges to assuring access to oncology services. J J Oncol Pract. 2007;3(2):79-86.

19. Lewis RA, Neal RD, Williams NH, et al. Follow-up of cancer in primary care versus secondary care: systematic review. Br J Gen Pract. 2009;59(564):234.

20. Johansson B, Holmberg L, Berglund G, et al. Reduced utilisation of specialist care among elderly cancer patients: a randomised study of a primary healthcare intervention. Eur J Cancer. 2001;37(17):2161-2168.

21. Nathan PC, Greenberg ML, Ness KK, et al. Medical care in long-term survivors of childhood cancer: a report from the childhood cancer survivor study. J Clin Oncol. 2008;26(27):4401-4409.

22. Oeffinger KC, Mertens AC, Hudson MM, et al. Health care of young adult survivors of childhood cancer: a report from the Childhood Cancer Survivor Study. Ann Fam Med. 2004;2(1):61-70.

23. Oeffinger KC, Wallace WHB. Barriers to follow-up care of survivors in the United States and the United Kingdom. Pediatr Blood Cancer. 2006;46(2):135-142.

24. Weller DP, Harris MF. Cancer care: what role for the general practitioner? Med J Aust. 2008; 189(2):59-60.

25. Grunfeld E, Levine MN, Julian JA, et al. Randomized trial of long-term follow-up for early-stage breast cancer: a comparison of family physician versus specialist care. J Clin Oncol. 2006;24(6):848-855.

26. Grunfeld E, Fitzpatrick R, Mant D, et al. Comparison of breast cancer patient satisfaction with follow-up in primary care versus specialist care: results from a randomized controlled trial. Br J Gen Pract. 1999;49(446):705.

27. Murray SA, Boyd K, Campbell C, et al. Implementing a service users' framework for cancer care in primary care: an action research study. Fam Pract. 2008;25(2):78-85.

28. Jiwa M, McManus A, Dadich A. Continuity of cancer care: where do primary care practitioners fit in? Cancer Forum. 2013;37(1):31-34.

29. Emery J, Trevena L, Mazza D, et al. The role of primary and community-based healthcare professionals in early detection and follow-up in cancer care - a rapid review of best practice models: an evidence check rapid review brokered by the Sax Institute for the Cancer Institute NSW. 2012. Available at: https:// www.saxinstitute.org.au/wp-content/uploads/REPORT_Role-of-PHC-cancerearly-detection-2smallpdf.com_.pdf. Accessed May 2, 2016

30. Nekhlyudov L. "Doc, should I see you or my oncologist?": a primary care perspective on opportunities and challenges in providing comprehensive care for cancer survivors. J Clin Oncol. 2009;27(15):2424-6.

31. Hauer KE, Durning SJ, Kernan WN, et al. Factors associated with medical students' career choices regarding internal medicine. JAMA. 2008;300(10): 1154-1164.

32. Duffey-Lind EC, O'Holleran E, Healey M, Vettese M, Diller L, Park ER. Transitioning to survivorship: a pilot study. J Pediatr Oncol Nurs. 2006;23(6):335-43.

33. Singer S, Gianinazzi ME, Hohn A, Kuehni CE, Michel G. General practitioner involvement in follow-up of childhood cancer survivors: a systematic review. Pediatr Blood Cancer. 2013;60(10):1565-73.

34. Campbell NC, MacLeod U, Weller D. Primary care oncology: essential if high quality cancer care is to be achieved for all. Fam Pract. 2002;19(6):577-578

35. Moher D, Liberati A, Tetzlaff J, Altman DG. Preferred reporting items for systematic reviews and meta-analyses: the PRISMA statement. Ann Intern Med. 2009;151(4):264-269.

36. Atkins D, Best D, Briss PA, et al. Grading quality of evidence and strength of recommendations. BMJ. 2004;328(7454):1490.

37. Robinson JK, Dellavalle RP, Bigby M, Callen JP. Systematic reviews: grading recommendations and evidence quality. Arch Dermatol. 2008; 144(1):97-9.

38. Anvik T, Holtedahl KA, Mikalsen H. "When patients have cancer, they stop seeing me" - The role of the general practitioner in early follow-up of patients with cancer - A qualitative study. BMC Fam Pract. 2006; 7(19).

39. Aubin M, Vezina L, Verreault R, et al. Patient, primary care physician and specialist expectations of primary care physician involvement in cancer care. J Gen Intern Med. 2012;27(1):8-15

40. Bober SL, Recklitis CJ, Campbell EG, et al. Caring for cancer survivors: a survey of primary care physicians. Cancer. 2009;115(18 Suppl):4409-18.

41. Brazil K, Sussman J, Bainbridge D, Whelan T. Who is responsible? The role of family physicians in the provision of supportive cancer care. $\mathrm{J}$ Oncol Pract. 2010;6(1):19-24.

42. Cheung WY, Neville BA, Cameron DB, Cook EF, Earle CC. Comparisons of patient and physician expectations for cancer survivorship care. J Clin Oncol. 2009;27(15):2489-95.
43. Dahlhaus A, Vanneman N, Guethlin C, Behrend J, Siebenhofer A. German general practitioners' views on their involvement and role in cancer care: a qualitative study. Fam Pract. 2014;31(2):209-14.

44. Del Giudice ME, Grunfeld E, Harvey BJ, Piliotis E, Verma S. Primary care physicians' views of routine follow-up care of cancer survivors. J Clin Oncol. 2009;27(20):3338-45.

45. Demagny L, Holtedahl K, Bachimont J, Thorsen T, Letourmy A, Bungener M. General practitioners' role in cancer care: a FrenchNorwegian study. BMC Res Notes. 2009;2(1):200.

46. Forsythe LP, Alfano CM, Leach CR, Ganz PA, Stefanek ME, Rowland JH. Who provides psychosocial follow-up care for post-treatment cancer survivors? A survey of medical oncologists and primary care physicians. J Clin Oncol. 2012;30(23):2897-905.

47. Geelen E, Krumeich A, Schellevis FG, van den Akker M. General practitioners' perceptions of their role in cancer follow-up care: a qualitative study in the Netherlands. Eur J Gen Pract. 2014;20(1):17-24.

48. Gilbert R, Willan A, Richardson S, Sellick S. Survey of family physicians: what is their role in cancer patient care? Can J Oncol. 1994;4(3):285.

49. Greenfield DM, Absolom K, Eiser C, et al. Follow-up care for cancer survivors: the views of clinicians. Br J Cancer. 2009;101(4):568-74.

50. Grunfeld E, Mant D, Vessey MP, Fitzpatrick R. Specialist and general practice views on routine follow-up of breast cancer patients in general practice. Fam Pract. 1995;12(1):60-5.

51. Johansen ML, Holtedahl KA, Rudebeck CE. A doctor close at hand: how GPs view their role in cancer care. Scand $\mathrm{J}$ Prim Health Care. 2010;28(4):249-55.

52. Johnson CE, Lizama N, Garg N, Ghosh M, Emery J, Saunders C. Australian general practitioners' preferences for managing the care of people diagnosed with cancer. Asia Pac J Clin Oncol. 2013;10(2):e90-98.

53. Kisker CT, Fethke CC, Tannous R. Shared management of children with cancer. Arch Pediatr Adolesc Med. 1997;151(10):1008-13.

54. Klabunde CN, Ambs A, Keating NL, et al. The role of primary care physicians in cancer care. J Gen Intern Med. 2009;24(9): 1029-36.

55. Larue F, Colleau SM, Fontaine A, Brasseur L. Oncologists and primary care physicians' attitudes toward pain control and morphine prescribing in France. Cancer. 1995;76(11):2375-2382.

56. McConnell D, Butow PN, Tattersall MHN. Improving the letters we write: An exploration of doctor-doctor communication in cancer care. $\mathrm{Br} \mathrm{J}$ Cancer. 1999;80(3-4):427-437.

57. Merport A, Lemon SC, Nyambose J, Prout MN. The use of cancer treatment summaries and care plans among Massachusetts physicians. Support Care Cancer. 2012;20(7):1579-1583.

58. Mitchell GK, Burridge LH, Colquist SP, Love A. General Practitioners' perceptions of their role in cancer care and factors which influence this role. Health Soc Care Community. 2012;20(6):607-616.

59. Nathan PC, Daugherty CK, Wroblewski KE, et al. Family physician preferences and knowledge gaps regarding the care of adolescent and young adult survivors of childhood cancer. J Cancer Surviv. 2013;7(3):27582 .

60. Nissen MJ, Beran MS, Lee MW, Mehta SR, Pine DA, Swenson KK. Views of primary care providers on follow-up care of cancer patients. Fam Med. 2007;39(7):477.

61. O'Beirne M, Verhoef M, Paluck E, Herbert C. Complementary therapy use by cancer patients. Physicians' perceptions, attitudes, and ideas. Can Fam Physician. 2004;50:882-888.

62. Paradiso A, Nitti P, Frezza P, Scorpiglione N. A survey in Puglia: the attitudes and opinions of specialists, general physicians and patients on follow-up practice. Ann Oncol. 1995;6(Suppl 2):53-6.

63. Potosky AL, Han PK, Rowland J, et al. Differences between primary care physicians' and oncologists' knowledge, attitudes and practices regarding the care of cancer survivors. J Gen Intern Med. 2011;26(12):1403-10.

64. Roorda C, Berendsen AJ, Haverkamp M, van der Meer K, de Bock GH. Discharge of breast cancer patients to primary care at the end of hospital follow-up: a cross-sectional survey. Eur J Cancer. 2013;49(8):1836-44.

65. Sada YH, Street RL Jr, Singh H, Shada RE, Naik AD. Primary care and communication in shared cancer care: a qualitative study. Am J Manag Care. 2011;17(4):259-65.

66. van Roosmalen SL, Pols A, Willems DL. Knowledge of Dutch GPs in caring for cancer patients using oral anticancer therapy at home. Fam Pract. 2013;30(6):666-670.

67. Wind J, Duineveld LA, van der Heijden RP, van Asselt KM, Bemelman WA, van Weert HC. Follow-up after colon cancer treatment in the Netherlands; a survey of patients, GPs, and colorectal surgeons. Eur J Surg Oncol. 2013;39(8):837-43.

68. Worster A, Bass MJ, Wood ML. Willingness to follow breast cancer. Survey of family physicians. Can Fam Physician. 1996;42:263. 
69. Zitzelsberger L, Grunfeld E, Graham ID. Family physicians' perspectives on practice guidelines related to cancer control. BMC Fam Pract. 2004;5:25.

70. DiCicco-Bloom B, Cunningham RS. The experience of information sharing among primary care clinicians with cancer survivors and their oncologists. J Cancer Surviv. 2013;7(1):124-130.

71. Cohen Castel O, Ungar L, Alperin M, Amiel GE, Karkabi K. Family physicians' perceptions, beliefs, and attitudes regarding information sharing with prostate cancer patients throughout the course of the disease. Support Care Cancer. 2008;16(8):955-61.
72. Kerrigan D, Waters $\mathbf{P}$, Ryan M, et al. Follow-up arrangements for breast cancer patients; is it appropriate to transfer surveillance to general practitioners? Ir Med J. 2014;107(9):273-5.

73. Britt H, Miller GC, Charles J, et al. General practice activity in Australia 2008-09. Australian Institute of Health and Welfare, University of Sydney. 2009.

74. Earle C. Long term care planning for cancer survivors: a health services research agenda. J Cancer Surviv. 2007;1(1):64-74. 